\title{
BMJ Open Utilisation of helicopter emergency medical services in the early medical response to major incidents: a systematic literature review
}

\author{
Anne Siri Johnsen, ${ }^{1,2,3}$ Sabina Fattah, ${ }^{1,4}$ Stephen J M Sollid, ${ }^{1,2}$ Marius Rehn ${ }^{1,2,5}$
}

To cite: Johnsen AS, Fattah S, Sollid SJM, et al. Utilisation of helicopter emergency medical services in the early medical response to major incidents: a systematic literature review. BMJ Open 2016;6:e010307. doi:10.1136/bmjopen-2015010307

- Prepublication history and additional material is available. To view please visit the journal (http://dx.doi.org/ 10.1136/bmjopen-2015010307).

Received 20 0ctober 2015 Revised 18 December 2015 Accepted 14 January 2016

CrossMark

For numbered affiliations see end of article.

Correspondence to Dr Anne Siri Johnsen; anne.siri.johnsen@ norskluftambulanse.no

\section{ABSTRACT}

Objective: This systematic review identifies, describes and appraises the literature describing the utilisation of helicopter emergency medical services (HEMS) in the early medical response to major incidents.

Setting: Early prehospital phase of a major incident. Design: Systematic literature review performed according to Preferred Reporting Items for Systematic Reviews and Meta-Analyses (PRISMA) guidelines. MEDLINE, EMBASE, the Cochrane Central Register of Controlled Trials, the Web of Science, PsycINFO, Scopus, Cinahl, Bibsys Ask, Norart, Svemed and UpToDate were searched using phrases that combined HEMS and 'major incidents' to identify when and how HEMS was utilised. The identified studies were subjected to data extraction and appraisal.

Results: The database search identified 4948 articles. Based on the title and abstract, the full text of 96 articles was obtained; of these, 37 articles were included in the review, and an additional five were identified by searching the reference lists of the 37 articles. HEMS was used to transport medical and rescue personnel to the incident and to transport patients to the hospital, especially when the infrastructure was damaged. Insufficient air traffic control, weather conditions, inadequate landing sites and failing communication were described as challenging in some incidents.

Conclusions: HEMS was used mainly for patient treatment and to transport patients, personnel and equipment in the early medical management of major incidents, but the optimal utilisation of this specialised resource remains unclear. This review identified operational areas with improvement potential. A lack of systematic indexing, heterogeneous data reporting and weak methodological design, complicated the identification and comparison of incidents, and more systematic reporting is needed.

Trial registration number: CRD42013004473.

\section{INTRODUCTION}

Major incidents remain a major global health challenge. In 2013, natural-triggered disasters killed more than 20000 people, created almost 100 million victims and
Strengths and limitations of this study

- This is a systematic literature review that follows the Preferred Reporting Items for Systematic Reviews and Meta-Analyses (PRISMA) guidelines.

- The protocol was published before conducting the study to avoid data-driven decisions; deviations from the protocol are noted in the article.

- Only literature in English and in Scandinavian languages is included.

caused enormous economic damage worldwide. $^{1}$ These numbers are only for natural disasters and do not take into account other types of major incidents. Major incidents are characterised by the need for an extraordinary medical response. They are heterogeneous by nature and their unexpectedness remains a challenge for emergency medical services (EMS). Fundamental for an effective major incident response is a robust and resilient EMS system. ${ }^{2}$ These systems can provide rapid access to advanced major incident management to improve patient outcome ${ }^{3}$ and optimise resource allocation as demand often exceeds capacity. ${ }^{4}$

Helicopters are obvious resources in major incident management through their capacity to bring specialised teams and equipment to incident scenes. They can also transport patients, provide search and rescue services, and perform overhead surveillance. When a site is remote or difficult to access, helicopters may be the only way to transport personnel, equipment and patients in and out of it. ${ }^{5-9}$ Following the first organised use of helicopters for military medevac during the Korean War, ${ }^{10}$ the use of helicopters for civilian patient transportation was introduced in the USA in the early 1970 s. ${ }^{11}$ It was later integrated as helicopter EMS (HEMS) in most high-income countries. $^{12-14}$ Although HEMS is embedded in most emergency response plans, the optimal 
use of this limited resource in the early medical management of major incidents remains unclear.

We aimed to systematically identify, describe and appraise the literature that describes the utilisation of HEMS in the early medical response to major incidents, to better address common challenges and to facilitate future research.

\section{METHODS}

\section{Study identification}

The protocol was published prior to conducting the literature $\operatorname{search}^{15}$ and registered in PROSPERO (CRD42013004473). A comprehensive literature search was performed to identify all relevant articles available as of 19 March 2015. The following databases were searched: MEDLINE, EMBASE, the Cochrane Central Register of Controlled Trials, the Web of Science, PsycINFO, Scopus, Cinahl, Bibsys Ask, Norart, Svemed and UpToDate. An additional search was performed in PubMed in order to retrieve articles that had not yet been entered into MEDLINE. The search was designed using Medical Subject Headings and related terms as keywords. This search was then adapted for use in the other databases (see online supplementary additional file I). In the absence of universally accepted nomenclature, literature that defined their incident as a major incident or disaster was included.

\section{Study eligibility and selection}

Inclusion criteria:

Articles that describe the use of HEMS in the early medical management of a major incident.

Exclusion criteria:

- Articles in languages other than English and Scandinavian

- Articles without abstracts

- Book chapters, conference abstracts, letters to the editor and editorials

Deviations from the protocol on inclusion and exclusion criteria. ${ }^{15}$

- Inclusion of commentaries

- Exclusion of literature where:

- Only fixed-wing aircraft were used

- Helicopters without dedicated medical capacity were used

- Incidents were considered to be part of military conflicts

- HEMS was used in the later recovery phase of the response.

The reason for the inclusion of commentaries was that these did not provide less relevant information than case reports. Exclusion criteria were adjusted to better target civilian medical helicopter response to major incidents in the acute phase.

\section{Search findings}

All studies were collected in an Endnote bibliographic database (2011; Thomson Reuters, USA). One author
(ASJ) scanned the titles and abstracts, and excluded articles that clearly did not meet the inclusion criteria. Full-text versions of the remaining articles were obtained and divided among pairs of authors (ie, ASJ and MR, SF and SJMS) for further screening, using the criteria listed above. Excluded articles were listed with the reason(s) for exclusion. If there was any uncertainty about whether a study should be included, there was a discussion until a consensus was reached among all of the authors. The reference lists of the studies that were included initially were examined individually to identify the additional relevant literature.

\section{Data extraction and appraisal}

ASJ appraised the quality of the included studies and extracted predefined data from the included articles into an Excel spreadsheet (2010; Microsoft, USA). Data extraction included the demography of incident area and characteristics regarding HEMS, major incident, incident response and patient characteristics. The data extraction variables were pilot-tested on four randomly selected articles before the protocol was published..$^{15}$ The appraisal items were selected by the authors, and aimed to describe the internal and external validity of the included studies. All data extraction and appraisal results were agreed on by another co-author.

\section{RESULTS}

\section{Literature search}

The search identified 4948 records (2763 after duplicates were removed), and the full-text versions of 96 articles were obtained. Of these, 37 articles $^{6-9}{ }^{16-48}$ were included in the study, and an additional $5^{49-53}$ were identified by searching through the reference lists of the 37 articles. Thus, the review included a total of 42 articles (table 1), with 59 articles excluded for various reasons (see online supplementary additional file II). The Preferred Reporting Items for Systematic Reviews and Meta-Analyses (PRISMA) diagram (figure 1) shows the inclusion and exclusion of articles in the different phases of this review. ${ }^{54}$

\section{Data extraction}

None of the included articles contained all of the items on the data extraction list (figure 2). Basic information about the affected area was described in 12 articles (29\%), information about the affected population in 24 $(57 \%)$ and scene access in 29 articles (69\%). Most papers described the characteristics of the incident. A timeline for the incident response was present in 25 articles $(59 \%)$ and a description of personnel in 35 $(83 \%)$ articles. In $12(29 \%)$ of the articles, there was a lack of resources, prehospital surge capacity was reported in $2(5 \%)$, and the response time was documented in 19 articles (45\%). Communications and coordination were described in 34 articles $(81 \%)$, and were in most cases failing. Scene safety was reported to 
Table 1 Study methods and use of HEMS

\begin{tabular}{|c|c|c|}
\hline & Method & Described use of HEMS \\
\hline Afzali et $a l^{16}$ & Prospective observational study & $\begin{array}{l}\text { Brought extra equipment for advanced life support. } \\
\text { HEMS doctor was Medical Incident Officer in three } \\
\text { major incidents }\end{array}$ \\
\hline Almersjø et a $f^{49}$ & Case report & $\begin{array}{l}\text { Performed search and rescue and secondary } \\
\text { transfers }\end{array}$ \\
\hline Ammons et $a l^{17}$ & Case report & $\begin{array}{l}\text { Evacuated the most severely injured patients to } \\
\text { hospitals and brought extra equipment to the scene }\end{array}$ \\
\hline Assa et $a l^{7}$ & Case report & $\begin{array}{l}\text { Brought extra personnel and equipment to the scene. } \\
\text { Air-medical crews assisted ground units in triage and } \\
\text { treatment. Transportation of casualties from the } \\
\text { remotely located scene to trauma centres. Allowed } \\
\text { distribution of patients between various centres in the } \\
\text { region }\end{array}$ \\
\hline Bland $^{18}$ & Case report & $\begin{array}{l}\text { Command, triage, treatment and transport. Author } \\
\text { was Forward Medical Incident Officer at Kings Cross } \\
\text { scene }\end{array}$ \\
\hline $\begin{array}{l}\text { Bovender and } \\
\text { Carey }^{19}\end{array}$ & Case report & $\begin{array}{l}\text { Used for more than } 200 \text { helicopter sorties from } \\
\text { flooded hospital }\end{array}$ \\
\hline Brandsjø et $a^{50}$ & Case report & $\begin{array}{l}\text { Rescued main proportion of survivors, because } \\
\text { nearby ships could not perform sea rescue }\end{array}$ \\
\hline $\begin{array}{l}\text { Brandstrom } \\
\text { et } a \text { fO }^{-}\end{array}$ & Case report & Search and Rescue \\
\hline Buerk et $a^{P^{1}}$ & Case report, design not clearly described & $\begin{array}{l}\text { Evacuated severely injured patients. Caused } \\
\text { disruption of radio communication and destroyed an } \\
\text { aid station. The possibility of collision was a concern }\end{array}$ \\
\hline $\begin{array}{l}\text { Buhrer and } \\
\text { Tilney }\end{array}$ & Case report & $\begin{array}{l}\text { Patient transport with advanced life support and a } \\
\text { secondary transfer to a burn centre }\end{array}$ \\
\hline Carlascio et $a^{23}$ & Case report, design not clearly described & $\begin{array}{l}\text { Secondary transfers and rescued one patient. } \\
\text { Brought extra crew and blood products }\end{array}$ \\
\hline $\begin{array}{l}\text { Cassuto and } \\
\text { Tarnow }^{24}\end{array}$ & Case report, design not clearly described & Secondary transfers from urban fire disaster \\
\hline Cocanour et $a^{25}$ & $\begin{array}{l}\text { Case report, describing same type of incident as } \\
\text { Bovender and Nates }\end{array}$ & $\begin{array}{l}\text { Evacuated patients from a flooded hospital. Used for } \\
\text { longer distance transport }\end{array}$ \\
\hline $\begin{array}{l}\text { Eckstein and } \\
\text { Cowen }^{26}\end{array}$ & Case report & Not clearly described \\
\hline Felix $\mathrm{Jr}^{27}$ & $\begin{array}{l}\text { Summarizes HEMS in USA in the early } 1970 \text { s } \\
\text { with a major incident case report }\end{array}$ & $\begin{array}{l}\text { Flew equipment to two damaged hospitals and } \\
\text { transferred patients to other hospitals }\end{array}$ \\
\hline Franklin et $a^{28}$ & Case report & $\begin{array}{l}\text { Patient transport from flooded areas to hospital and } \\
\text { brought health personnel to places where they were } \\
\text { needed }\end{array}$ \\
\hline Furukawa ${ }^{28}$ & Case report & $\begin{array}{l}\text { Transported personnel to the remote site of an } \\
\text { airplane crash and airlifted survivors and dead from } \\
\text { the scene }\end{array}$ \\
\hline Iselius ${ }^{29}$ & $\begin{array}{l}\text { Case report describing the same incident as } \\
\text { Oestern }\end{array}$ & $\begin{array}{l}\text { Evacuation of injured passengers from railway } \\
\text { accident. Brought extra crew and equipment to the } \\
\text { site }\end{array}$ \\
\hline Jacobs et $\left.a\right|^{\beta 0}$ & $\begin{array}{l}\text { Review of seven major incidents in one HEMS } \\
\text { service describing the same inci- dents as } \\
\text { Stohler }\end{array}$ & $\begin{array}{l}\text { Used for evacuation and transport of the most } \\
\text { critically injured patients to trauma centres. Distributed } \\
\text { them to different centres, so not to overwhelm the } \\
\text { closest one }\end{array}$ \\
\hline $\begin{array}{l}\text { Lavery and } \\
\text { Horan }^{31}\end{array}$ & Case report & Primary and secondary transport of injured patients \\
\hline Lavon et $a^{\beta 2}$ & Two case reports & $\begin{array}{l}\text { Brought extra personnel, equipment and command } \\
\text { team to the local hospital. Participated in secondary } \\
\text { transfer with advanced trauma life support to larger } \\
\text { trauma centre }\end{array}$ \\
\hline Leiba et $a /^{\beta 3}$ & $\begin{array}{l}\text { Case report describing the same incident as } \\
\text { Lavon }\end{array}$ & $\begin{array}{l}\text { Brought extra personnel and blood products to the } \\
\text { closest hospital and evacuated patients }\end{array}$ \\
\hline
\end{tabular}


Table 1 Continued

\begin{tabular}{|c|c|c|}
\hline & Method & Described use of HEMS \\
\hline Leiba et $a \beta^{34}$ & $\begin{array}{l}\text { Case report describing the same incident as } \\
\text { Assa. The DISAST-CIR methodology of reporting } \\
\text { also used by Schwartz }\end{array}$ & $\begin{array}{l}\text { Primary transport of injured to different hospitals } \\
\text { ensuring that the closest hospital did not reach surge } \\
\text { capacity }\end{array}$ \\
\hline Lockey et $a \beta^{35}$ & $\begin{array}{l}\text { Case report describing the same incident as } \\
\text { Bland }\end{array}$ & $\begin{array}{l}\text { Deployed staff and equipment to the scenes and staff } \\
\text { from home to the hospitals. Allowed rapid deployment } \\
\text { in difficult traffic conditions }\end{array}$ \\
\hline $\begin{array}{l}\text { Lyon and } \\
\text { Sanders }\end{array}$ & Commentary of a case report & $\begin{array}{l}\text { Brought pre-hospital doctors to the scene for medical } \\
\text { incident command and advanced interventions. } \\
\text { Transported the patients directly to specialist } \\
\text { paediatric trauma centres }\end{array}$ \\
\hline Malik et $a \beta^{37}$ & $\begin{array}{l}\text { Observational study of scoring systems in a } \\
\text { major incident in remote area }\end{array}$ & $\begin{array}{l}\text { Transported personnel to the incident. Secondary } \\
\text { transport of priority I patients to trauma centre }\end{array}$ \\
\hline $\begin{array}{l}\text { Martchenke } \\
\text { et } a \beta^{8}\end{array}$ & $\begin{array}{l}\text { Case report, interviewing all participating HEMS } \\
\text { members involved }\end{array}$ & $\begin{array}{l}\text { Triage, treatment and transport of patients from } \\
\text { earthquake }\end{array}$ \\
\hline Martin $^{51}$ & Case report & $\begin{array}{l}\text { Helicopter and personnel present at event. Tasks not } \\
\text { specified }\end{array}$ \\
\hline $\begin{array}{l}\text { Matsumoto } \\
\text { et } a^{\beta 9}\end{array}$ & Case report & $\begin{array}{l}\text { Mainly used for patient transportation and evacuation. } \\
\text { Also transported food, water and generators to } \\
\text { destroyed hospitals }\end{array}$ \\
\hline Nates $^{40}$ & $\begin{array}{l}\text { Case report and review of literature. Describing } \\
\text { same type of incident as Bovender and }\end{array}$ & $\begin{array}{l}\text { Transport of patients from damaged hospital, vital in } \\
\text { evacuation because of damaged roads }\end{array}$ \\
\hline
\end{tabular}

Nia et $a^{p^{3}}$ Cocanour

Nicholas and Oberheide ${ }^{52}$

Nocera and

Dalton ${ }^{41}$

Case report and survey of survivor's opinions about health response

Case report describing the same incident as Ammons

Two case reports

\begin{tabular}{|c|c|}
\hline Oestern et $a{ }^{42}$ & $\begin{array}{l}\text { Case report describing the same incident as } \\
\text { Iselius }\end{array}$ \\
\hline Pokorny ${ }^{43}$ & Case report \\
\hline $\begin{array}{l}\text { Romundstad } \\
\text { et } \mathrm{al}^{44}\end{array}$ & Case report \\
\hline $\begin{array}{l}\text { Schwartz and } \\
\text { Bar-Dayan }^{45}\end{array}$ & $\begin{array}{l}\text { Case report presented in DISAST-CIR } \\
\text { met-hodology for uniform presentation. Leiba } \\
2009 \text { used same methodology }\end{array}$ \\
\hline Sollid et $a f^{46}$ & Case report \\
\hline
\end{tabular}

Evacuated injured from the earthquake zone and brought resources and equipment to affected area Transport from primary to secondary health care facility. Brought supplies to scene

Transport of experienced crew to the scene.

Performed advanced life-saving procedures in one of the incidents

Transported patients to more remote hospitals

Evacuation of victims in flooded area, otherwise not specified.

Arriving HEMS doctor was appointed Medical Incident Commander and organized medical resources in teams. Transported some of the patients to more remote hospitals

Patient transport of the most seriously injured patients

Flew out extra personnel and stretchers. Triaged and treated patients acted as medical incident commander and transported the most severely injured from one of the incident sites

\begin{tabular}{|c|c|}
\hline Spano et a ${ }^{\rho}$ & Case report \\
\hline Stohler et $a^{\beta}$ & $\begin{array}{l}\text { Retrospective review of four major incidents. } \\
\text { Same incidents as Jacobs }\end{array}$ \\
\hline $\begin{array}{l}\text { Urquieta and } \\
\text { Varon }^{47}\end{array}$ & Case report \\
\hline Yi-Szu et $a^{48}$ & $\begin{array}{l}\text { Case report, analysing patterns and outcomes of } \\
\text { patients with chest injuries }\end{array}$ \\
\hline
\end{tabular}

Brought personnel and equipment to site and evacuated the patients when weather allowed The responses included bringing extra personnel and equipment to scene, triage, medical treatment, air surveillance and transport

Triage and transport of severely injured victims

Secondary transport of patients from field hospitals in earthquake zone.

be an issue in 18 reports (43\%), and this was related to issues such as inadequate air traffic control, active shooters, inadequate landing sites and bad weather. HEMS tasks included patient evacuation and transport from scene as well as transport of supplies, personnel and equipment to the scene. The literature also described HEMS being used for secondary transport, treatment, leadership and on-scene triage. In addition, HEMS was 


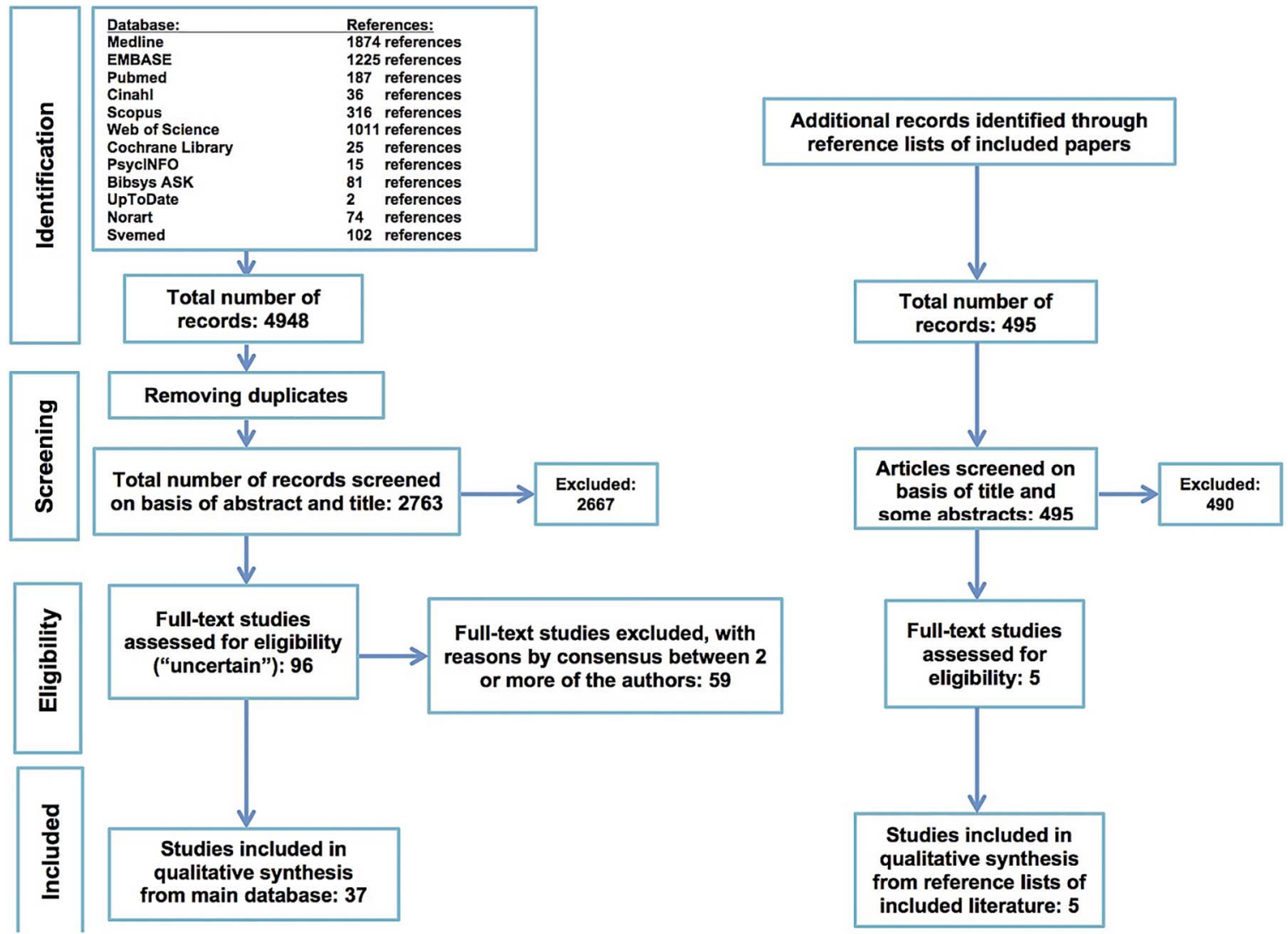

Figure 1 Preferred Reporting Items for Systematic Reviews and Meta-Analyses (PRISMA).

in some incidents utilised for search and rescue, and for air surveillance (table 1 ).

\section{Appraisal}

We sought to identify data items related to internal and external validity. Of the included articles, 19 (45\%) contained references to where the data were obtained. We found 5 articles (12\%) that reported no conflicts of interests and $1(2 \%)$ that reported a conflict of interests. No articles reported they had ethical approval, although $1(2 \%)$ stated that such approval was not needed. The description of both the HEMS and EMS structure before the incident was described in 12 (29\%), whereas 7 articles (17\%) described HEMS alone. The incident itself was clearly described in 40 articles $(95 \%)$. Study limitations were discussed in $5(12 \%)$, and the study design was described in 32 articles $(76 \%)$. The quality appraisal findings are shown in figure 3. The study methodology was as follows: Of the 42 included studies, 37 (88\%) were case reports, $2(5 \%)$ observational studies, $2(5 \%)$ reviews and $1(2 \%)$ was a summary of the use of HEMS combined with a case report (table 1).

\section{DISCUSSION}

This systematic literature review found little or no systematic reporting of the utilisation of HEMS in the early medical management of major incidents. HEMS were most often reported to be used in patient evacuation and transport from the scene, and in transport of supplies and personnel to the incident scene (table 1). Data relevant to depict internal and external validity, such as reference to data source and handling of missing data, were lacking (figure 3). Further, the heterogeneity of the literature and the overall weak methodological design made it difficult to evaluate the contribution of HEMS to the management of major incidents.

The included incidents had various logistical and geographical challenges. In the $7 / 7$ London terrorist bombings in 2005, a helicopter was used to deploy staff and equipment to urban scenes when road access was difficult. ${ }^{35}$ Use of a helicopter also allowed the deployment of staff from home at a time when public transportation was inaccessible in the city. In the 22/7 Utøya terrorist shootings in 2011, additional medical personnel were brought to the scene, which this time was a rural area with overloaded provincial roads. ${ }^{46}$ Other studies described how HEMS facilitated the transport of victims to the hospital, especially when the scene of the incident was difficult to access. ${ }^{49}{ }^{25}$ HEMS also helped in secondary transfers of patients with particular needs, such as transporting patients to dedicated burns units. ${ }^{24}$ Although scene safety remains a foremost priority in major incident management, this was discussed in less than half of the studies. The inability to fly due to bad weather $^{8}$ and the lack of designated landing sites ${ }^{19} 3147$ were described as operational hazards. Further, HEMS involvement in major incident management often 


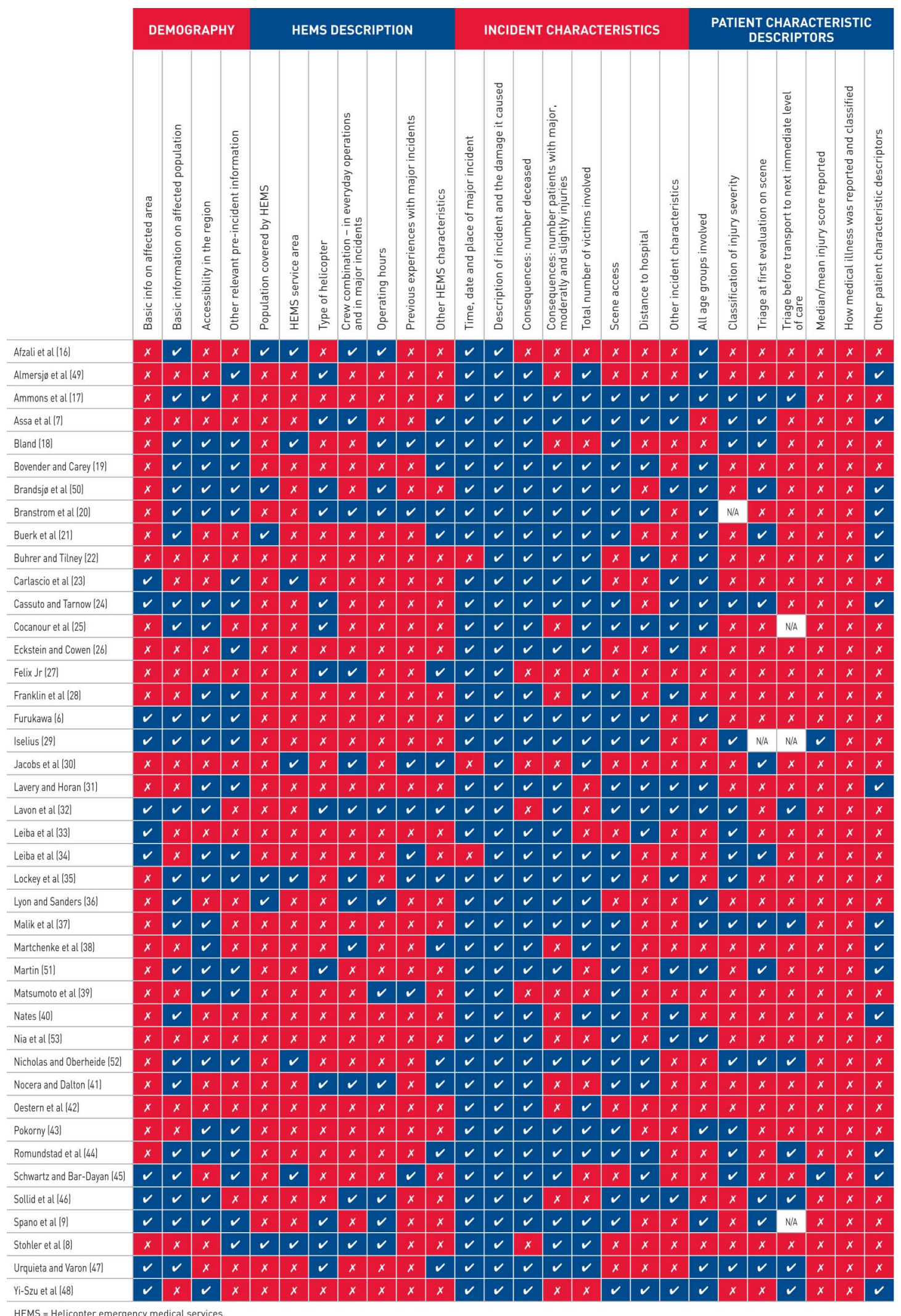

Figure 2 Data extraction.

involved multiple aircraft operating in uncontrolled air space, indicating insufficient air traffic control. $^{21} 23273846$ Future improvements in aviation traffic awareness systems, navigation and communication may mitigate the aviation risks. However, the emphasis should be on implementing procedures for multiple aircraft operations in uncontrolled air space. Crew training may also reduce the 
Figure 2 Continued

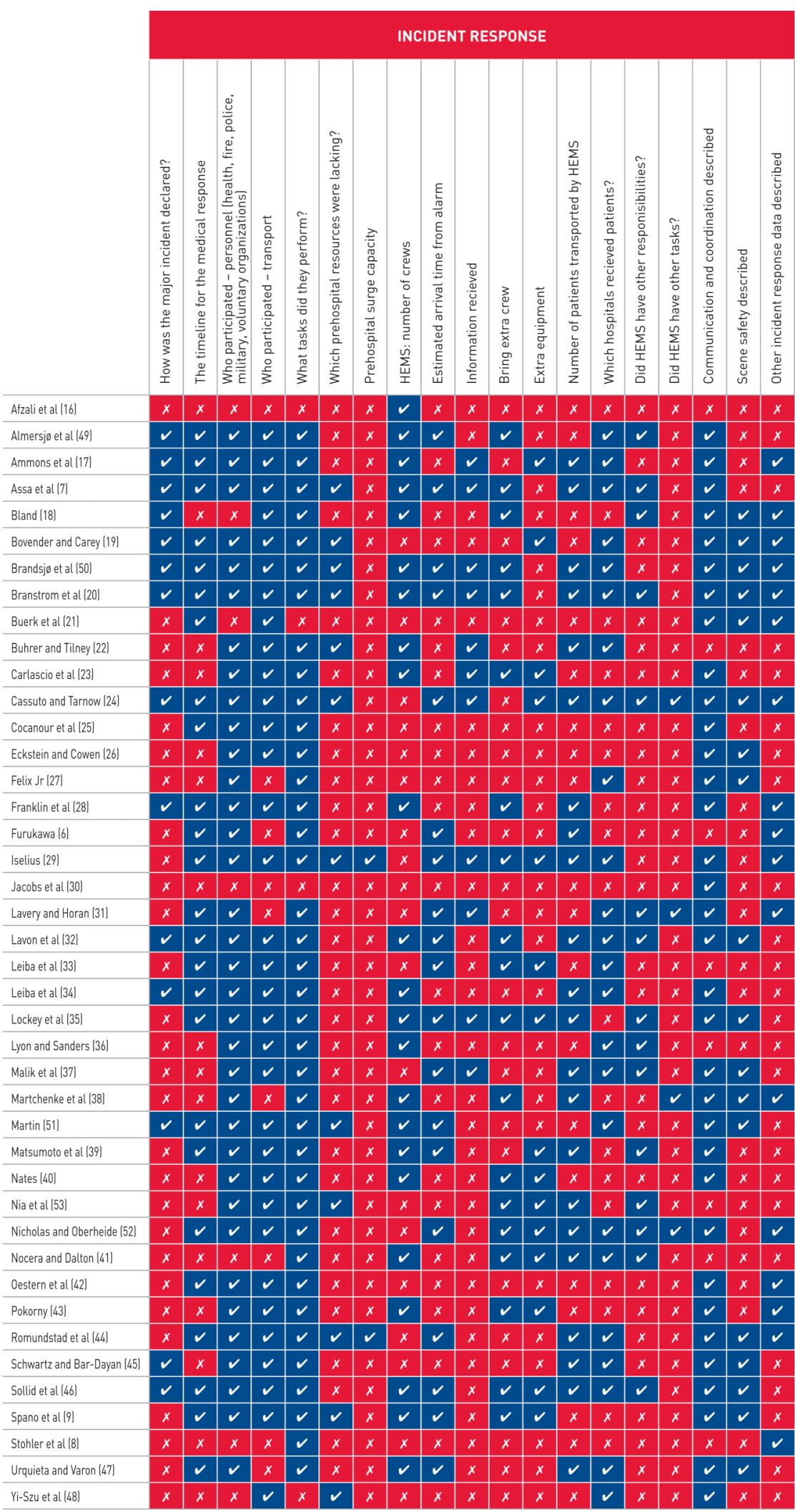

HEMS = Helicopter emergency medical services.

risks associated with confined area landings and bad weather flight operations.

The heterogeneous nature of major incidents is reflected by the lack of a common nomenclature. ${ }^{55}$
Several definitions of a major incident have been proposed that differ slightly from each other. ${ }^{56-58}$ To avoid excluding relevant articles, literature that defined their incident as a major incident or disaster was included. 


\begin{tabular}{|c|c|c|c|c|c|c|c|c|c|c|c|c|}
\hline & \multicolumn{5}{|c|}{ INTERNAL VALIDITY } & \multicolumn{7}{|c|}{ EXTERNAL VALIDITY } \\
\hline & 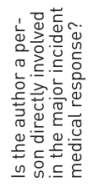 & 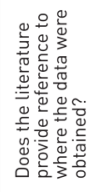 & 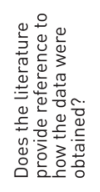 & 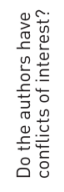 & 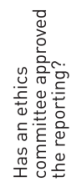 & 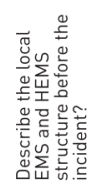 & 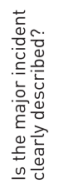 & 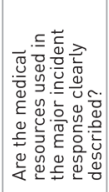 & 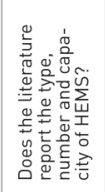 & 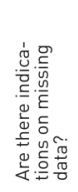 & 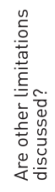 & 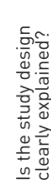 \\
\hline Afzali et al (16] & $?$ & $\checkmark$ & $\checkmark$ & $x$ & $x$ & $\checkmark$ & $x$ & $x$ & $\checkmark$ & $x$ & $x$ & $\checkmark$ \\
\hline Almersjo et al [49] & $x$ & $\checkmark$ & $\checkmark$ & $?$ & $?$ & $\checkmark$ & $\checkmark$ & $x$ & $\checkmark$ & $x$ & $x$ & $\checkmark$ \\
\hline Ammons et al (17) & $?$ & $x$ & $x$ & $?$ & $?$ & $v$ & $r$ & $v$ & $x$ & $x$ & $x$ & $\checkmark$ \\
\hline Assa et al (7] & $?$ & $\checkmark$ & $\checkmark$ & $?$ & $?$ & $x$ & $\checkmark$ & $v$ & $\checkmark$ & $x$ & $x$ & $\checkmark$ \\
\hline Bland (18) & $\checkmark$ & N/A & $\mathrm{N} / \mathrm{A}$ & $?$ & $?$ & $x$ & $r$ & $x$ & $x$ & $x$ & $x$ & $\checkmark$ \\
\hline Bovender and Carey (19) & $\checkmark$ & $x$ & $x$ & $?$ & $?$ & $x$ & $\checkmark$ & $x$ & $x$ & $x$ & $x$ & $\checkmark$ \\
\hline Brandsjø et al (50) & $x$ & $\checkmark$ & $\checkmark$ & $?$ & $?$ & $\checkmark$ & $r$ & $\checkmark$ & $\checkmark$ & $x$ & $x$ & $\checkmark$ \\
\hline Branstrom et al (20] & $x$ & 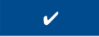 & $\checkmark$ & $?$ & $?$ & $\checkmark$ & $\checkmark$ & $v$ & $\checkmark$ & $x$ & $x$ & $\checkmark$ \\
\hline Buerk et al (21) & $?$ & $x$ & $x$ & $?$ & $?$ & $\checkmark$ & $r$ & $x$ & $x$ & $\checkmark$ & $x$ & $x$ \\
\hline Buhrer and Tilney (22) & $?$ & $x$ & $x$ & $?$ & $?$ & $x$ & $v$ & $x$ & Not capacity & $x$ & $x$ & $v$ \\
\hline Carlascio et al (23) & $\checkmark$ & $x$ & $x$ & $\checkmark$ & $?$ & Not EMS & $v$ & NotEMS & Not type & $x$ & $x$ & $x$ \\
\hline Cassuto and Tarnow (24) & $?$ & $x$ & $x$ & $?$ & $?$ & $x$ & $r$ & $r$ & $x$ & $x$ & $x$ & $x$ \\
\hline Cocanour et al (25) & $?$ & $x$ & $x$ & $?$ & $?$ & $x$ & $r$ & $x$ & $x$ & $x$ & $x$ & $v$ \\
\hline Eckstein and Cowen (26) & $?$ & $x$ & $x$ & $?$ & $?$ & $x$ & $\checkmark$ & $x$ & $x$ & $x$ & $x$ & $\sigma$ \\
\hline Felix Jr [27] & $?$ & Partly & $x$ & $?$ & $?$ & Not EMS & $\checkmark$ & $x$ & $x$ & $x$ & $x$ & $\checkmark$ \\
\hline Franklin et al (28) & $?$ & $x$ & $x$ & $?$ & $x$ & $x$ & $v$ & $v$ & $x$ & $x$ & $x$ & $x$ \\
\hline Furukawa $|6|$ & $?$ & $x$ & $x$ & $?$ & $?$ & $x$ & $r$ & $v$ & $x$ & $x$ & $x$ & $x$ \\
\hline Iselius (29) & $x$ & $v$ & $x$ & $?$ & $?$ & $x$ & $v$ & $\checkmark$ & $x$ & $x$ & $x$ & $v$ \\
\hline Jacobs et al (30) & $?$ & $\checkmark$ & $x$ & $?$ & $?$ & Not EMS & $x$ & $x$ & $x$ & $x$ & $x$ & $\checkmark$ \\
\hline Lavery and Horan (31) & $?$ & $x$ & $x$ & $x$ & $?$ & $x$ & $r$ & $x$ & $x$ & $x$ & $\checkmark$ & $x$ \\
\hline Lavon et al (32] & $?$ & $v$ & $\checkmark$ & $?$ & $?$ & $\checkmark$ & $\checkmark$ & $\checkmark$ & $\checkmark$ & $x$ & $\checkmark$ & $v$ \\
\hline Leiba et al (33) & $?$ & $r$ & $\checkmark$ & $?$ & $?$ & $x$ & $r$ & $x$ & $x$ & $x$ & $x$ & $r$ \\
\hline Leiba et al (34) & $?$ & $v$ & $v$ & $?$ & $?$ & $x$ & $v$ & $v$ & $x$ & $x$ & $x$ & $v$ \\
\hline Lockey et al (35) & $?$ & $\checkmark$ & $x$ & $?$ & $?$ & Noť EMS & $\checkmark$ & $x$ & $x$ & $\checkmark$ & $x$ & $\checkmark$ \\
\hline Lyon and Sanders (36) & $?$ & $x$ & $x$ & $x$ & $?$ & Not EMS & $\checkmark$ & $\checkmark$ & $x$ & $x$ & $x$ & $x$ \\
\hline Malik et al (37) & $?$ & $x$ & $x$ & $?$ & $?$ & $x$ & $\checkmark$ & $x$ & $x$ & $x$ & $\checkmark$ & $\checkmark$ \\
\hline Martchenke et al (38) & $?$ & $\checkmark$ & $\checkmark$ & $?$ & $?$ & $x$ & $\checkmark$ & $x$ & $x$ & $x$ & $x$ & $\checkmark$ \\
\hline Martin (51) & $\checkmark$ & $x$ & $x$ & $?$ & $?$ & $\checkmark$ & $\checkmark$ & $\checkmark$ & Not capacity & $x$ & $x$ & $x$ \\
\hline Matsumoto et al [39] & $?$ & $x$ & $x$ & $?$ & $?$ & Only DMMAT & $\checkmark$ & Only DMAT & $x$ & $x$ & $x$ & $x$ \\
\hline Nates (40) & $?$ & $x$ & $x$ & $?$ & $?$ & $x$ & $v$ & $x$ & $x$ & $x$ & $x$ & $v$ \\
\hline Nia et al (53) & $?$ & $r$ & $\checkmark$ & $?$ & $?$ & $x$ & $r$ & $x$ & $x$ & $x$ & $x$ & $v$ \\
\hline Nicholas and Oberheide (52) & $\checkmark$ & $x$ & $x$ & $?$ & $?$ & $\checkmark$ & $\checkmark$ & $x$ & $x$ & $x$ & $x$ & $x$ \\
\hline Nocera and Dalton (41) & $?$ & $x$ & $x$ & $?$ & $?$ & Nǒ̌ EMS & $\checkmark$ & $x$ & Not capacity & $x$ & $x$ & $\checkmark$ \\
\hline Oestern et al [42] & $?$ & $x$ & $x$ & $?$ & $?$ & $x$ & $r$ & $\checkmark$ & $x$ & $x$ & $x$ & $\checkmark$ \\
\hline Pokorny (43) & $?$ & $x$ & $x$ & $?$ & $?$ & $\checkmark$ & $\checkmark$ & $\checkmark$ & $x$ & $x$ & $x$ & $v$ \\
\hline Romundstad et al (44) & $\checkmark$ & $\checkmark$ & $\checkmark$ & $?$ & $?$ & $x$ & $\checkmark$ & $\checkmark$ & $\begin{array}{c}\text { Not capacity } \\
\text { and type }\end{array}$ & $x$ & $x$ & $r$ \\
\hline Schwartz and Bar-Dayan (45) & $\checkmark$ & $\checkmark$ & $\checkmark$ & $?$ & $?$ & $\checkmark$ & $\checkmark$ & $\checkmark$ & Not capacity & $x$ & $x$ & $\checkmark$ \\
\hline Sollid et al [46] & $?$ & $v$ & $\checkmark$ & $x$ & $\boldsymbol{V}^{*}$ & $x$ & $r$ & $\checkmark$ & $x$ & $x$ & $\checkmark$ & $r$ \\
\hline Spano et al (9] & $?$ & $\nu$ & $\checkmark$ & $x$ & $?$ & $\checkmark$ & $\checkmark$ & $\checkmark$ & $x$ & $\checkmark$ & $\checkmark$ & $\checkmark$ \\
\hline Stohler et al (8) & $?$ & $x$ & $x$ & $?$ & $?$ & Noť̃MS & $\checkmark$ & $x$ & $x$ & $x$ & $x$ & $\checkmark$ \\
\hline Urquieta and Varon (47) & $?$ & $x$ & $x$ & $?$ & $?$ & $x$ & $r$ & $\checkmark$ & $\checkmark$ & $x$ & $x$ & $v$ \\
\hline Yi-Szu et al (48) & $?$ & 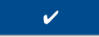 & $x$ & $?$ & $?$ & $x$ & $\checkmark$ & $x$ & $x$ & $x$ & $x$ & $\checkmark$ \\
\hline
\end{tabular}

*Applied, Committee concidered approval not neccessary. DMAT = Disaster medical assistance teams. EMS = Emergency medical services. HEMS = Helicopter emergency medical services.

Figure 3 Appraisal.

Our findings emphasise that a universally accepted definition of major incident is needed to facilitate comparative studies and to improve the accuracy of database indexing.
Our appraisal found that the majority of the included articles provided detailed descriptions of the incidents but that there was a tendency towards inadequate descriptions of the everyday HEMS system. The lack of 
baseline data made it difficult to evaluate the deployment and utilisation of extraordinary resources during major incidents. The methodological designs were generally weak and dominated by retrospective observational case reports. This is not surprising considering the difficulties in planning and executing prospective studies on major incidents. With an established template of standardised variables, a prospective study design can, however, be established to collect data from major incidents. If similar data are collected from major incident exercises in similar systems, a case-control design can even be applied to future studies. Such studies can be further strengthened by including other data sources such as focus group interviews from involved personnel in the sense of method triangulation. ${ }^{59} 60$ We also found that some incidents were described by several reports, indicating possible skewedness in the literature regarding high-profile incidents. As with all unstructured reporting, establishing a denominator for HEMS involvement proved difficult, again highlighting that future research should build on systematically collected data with uniform variable definitions to allow better comparisons. ${ }^{61}$

\section{Limitations}

The authors selected items for use in data extraction and appraisal that they assumed were relevant. However, these items do not represent a reference standard, since such a standard does not exist, to our knowledge.

Many major incidents occur in non-English-speaking countries; accordingly, it is a weakness that only articles in English and the Nordic languages were included. However, the included articles described incidents on different continents, which improve the generalisability of the findings. Further, we may have failed to identify some relevant studies, since articles without abstracts were not included, and a single author performed the initial screening.

\section{Conclusion}

This systematic literature review identified, described and appraised the literature on the utilisation of HEMS in the early medical management of major incidents. Heterogeneous data reporting complicated our efforts to identify and evaluate the overall utilisation of HEMS in such incidents. To address such shortcomings, systematic uniform reporting of HEMS in major incidents is called for.

\footnotetext{
Author affiliations

${ }^{1}$ Department of Research and Development, Norwegian Air Ambulance Foundation, Drøbak, Norway

${ }^{2}$ Department of Health Studies, Faculty of Social Sciences, University of Stavanger, Stavanger, Norway

${ }^{3}$ Department of Anaesthesiology, Oslo University Hospital, Oslo, Norway

${ }^{4}$ Anaesthesia and Critical Care Research Group, Faculty of Health Sciences, University of Tromsø, Tromsø, Norway

5London's Air Ambulance, Royal London Hospital, Barts Health Trust, London, UK
}

Acknowledgements The authors thank Marie Isachsen, Ullevål University Hospital Library, Oslo, Norway, who designed and conducted the literature search.

Contributors ASJ and MR conceived the study. ASJ, MR, SJMS and SF took part in study design, data analysis and writing of the manuscript, and approved the final version of the manuscript.

Funding All of the authors are employed by the Norwegian Air Ambulance Foundation, which played no part in the study design, data collection, data analysis, or manuscript preparation processes.

Competing interests None declared.

Provenance and peer review Not commissioned; externally peer reviewed.

Data sharing statement No additional data are available.

Open Access This is an Open Access article distributed in accordance with the Creative Commons Attribution Non Commercial (CC BY-NC 4.0) license, which permits others to distribute, remix, adapt, build upon this work noncommercially, and license their derivative works on different terms, provided the original work is properly cited and the use is non-commercial. See: http:// creativecommons.org/licenses/by-nc/4.0/

\section{REFERENCES}

1. Guha-Sapir D, Hoyois P, Below R. Annual disaster statistical review 2013: the numbers and trends. Brussels: Cred, 2014. http://www. cred.be/sites/default/files/ADSR_2013.pdf (accessed 3 Sep 2015).

2. Sasser $\mathrm{S}$, Varghese M, Kellermann A, et al. Prehospital trauma care systems. Geneva: World Health Organization, 2005.

3. Aylwin CJ, König TC, Brennan NW, et al. Reduction in critical mortality in urban mass casualty incidents: analysis of triage, surge, and resource use after the London bombings on July 7, 2005. Lancet 2006;368:2219-25.

4. Sasser S. Field triage in disasters. Prehosp Emerg Care 2006;10:322-3.

5. Butler DP, Anwar I, Willett $\mathrm{K}$. Is it the $\mathrm{H}$ or the EMS in HEMS that has an impact on trauma patient mortality? A systematic review of the evidence. Emerg Med J 2010;27:692-701.

6. Furukawa K, Kubo K. Accident of Japan Air Lines Flight 123 Boeing 747. Aircraft and dealing with the disaster. J Med Leg Droit Med 1994;37:157-66.

7. Assa A, Landau DA, Berenboim E, et al. Role of air-medical evacuation in mass-casualty incidents-a train collision experience. Prehosp Disaster Med 2009;24:271-6.

8. Stohler SA, Jacobs LM, Gabram SGA. Roles of a helicopter emergency medical service in mass casualty incidents. J Air Med Transp 1991;10:7-13.

9. Spano SJ, Campagne D, Stroh G, et al. A lightning multiple casualty incident in Sequoia and Kings Canyon national parks. Wilderness Environ Med 2015;26:43-53.

10. Driscoll RS. New York chapter history of military medicine award. U.S. Army medical helicopters in the Korean war. Mil Med 2001;166:290-6.

11. Jacobs LM, Bennett B. A critical care helicopter system in trauma. J Natl Med Assoc 1989;8:1157-67.

12. Taylor $\mathrm{C}$, Jan $\mathrm{S}$, Curtis $\mathrm{K}$, et al. The cost-effectiveness of physician staffed Helicopter Emergency Medical Service (HEMS) transport to a major trauma centre in NSW, Australia. Injury 2012;43:1843-9.

13. Salimi J, Khaji A, Khashayar P, et al. Helicopter emergency medical system in a region lacking trauma coordination (experience from Tehran). Emerg Med J 2009;26:361-4.

14. Krüger AJ, Skogvoll E, Castrén M, et al. Scandinavian pre-hospital physician-manned Emergency Medical Services-Same concept across borders? Resuscitation 2010;81:427-33

15. Johnsen AS, Fattah S, Sollid SJM, et al. Impact of helicopter emergency medical services in major incidents: systematic literature review. BMJ Open 2013;3:e003335.

16. Afzali M, Hesselfeldt R, Steinmetz J, et al. A helicopter emergency medical service May allow faster access to highly specialised care. Dan M J 2013;60:1-5.

17. Ammons MA, Moore EE, Pons PT, et al. The role of a regional trauma system in the management of a mass disaster: an analysis of the Keystone, Colorado, chairlift accident. J Trauma 1988;28:1469-71.

18. Bland SA. HEMS training and the 7th July 2005: a personal perspective. J R Nav Med Serv 2006;92:130-5. 
19. Bovender JO Jr, Carey B. A week we Don't want to forget: lessons learned from Tulane. Front Health Serv Manage 2006;23:3-12.; discussion 25-30.

20. Brandstrøm H, Sedig K, Lundalv J. Kamedo 77. MS Sleipners förlisning. Socialstyrelsen. 2003:1-96. https://www.socialstyrelsen. se/Lists/Artikelkatalog/Attachments/10743/2003-123-7_20031238.pdf (accessed 1 Oct 2015)

21. Buerk CA, Batdorf JW, Cammack KV, et al. MGM Grand Hotel Fire: lessons learned from a major disaster. Arch Surg 1982;117:641-4.

22. Buhrer $\mathrm{S}$, Tilney $\mathrm{P}$. Blast lung injury in a 20 -year-old man after a home explosion. Air Med J 2012;31:10-12.

23. Carlascio DR, McSharry MC, LeJeune CJ, et al. Air medical response to the 1990 Will County, Illinois, Tornado. J Air Med Transp 1991:10:7-16.

24. Cassuto J, Tarnow P. The discotheque fire in Gothenburg 1998. Burns 2003;29:405-16.

25. Cocanour CS, Allen SJ, Mazabob J, et al. Lessons learned from the evacuation of an Urban teaching hospital. Arch Surg 2002;137:1141-5.

26. Eckstein M, Cowen AR. Scene safety in the face of automatic weapons fire: a new dilemma for ems? Prehosp Emerg Care 1998;2:117-22.

27. Felix Jr WR. Metropolitan aeromedical service: state of the art. J Trauma 1976;16:873-81.

28. Franklin JA, Wiese W, Meredith JT, et al. Hurricane Floyd. N C Med J 2000;61:384-9.

29. Iselius L. Kamedo-79. Tågolyckan i Tyskland 1998 Socialstyrelsen. 2004:1-24. http://www.socialstyrelsen.se/Lists/ Artikelkatalog/Attachments/10414/2004-123-3_20041233.pdf (accessed 1 Oct 2015).

30. Jacobs LM, Gabram SGA, Stohler SA. The integration of a helicopter emergency medical service in a mass casualty response system. Prehosp Disaster Med 1991;6:451-4.

31. Lavery GG, Horan E. Clinical review: Communication and logistics in the response to the 1998 terrorist bombing in Omagh, Northern Ireland. Crit Care 2005:9:401-8.

32. Lavon O, Hershko D, Barenboim E. Large-scale airmedical transport from a peripheral hospital to level-1 trauma centres after remote mass-casualty incidents in Israel. Prehosp Disaster Med 2010;24:549-55.

33. Leiba A, Blumenfeld A, Hourvitz A, et al. Lessons learned from cross-border medical response to the terrorist bombings in Tabba and Ras-el-Satan, Egypt, on 07 October 2004. Prehosp Disaster Med 2005;20:253-7.

34. Leiba A, Schwartz D, Eran T, et al. DISAST-CIR: disastrous incidents systematic analysis through components, interactions and results: application to a large-scale train accident. J Emerg Med 2009;37:46-50.

35. Lockey DJ, MacKenzie R, Redhead J, et al. London bombings July 2005: the immediate pre-hospital medical response. Resuscitation 2005;66:ix-xii.

36. Lyon RM, Sanders J. The Swiss bus accident on 13 March 2012 : lessons for pre-hospital care. Crit Care 2012;16:138.

37. Malik ZU, Pervez M, Safdar A, et al. Triage and management of mass casualties in a train accident. $J$ Coll Physicians Surg Pak 2004;14:108-11.

38. Martchenke J, Lynch T, Pointer J, et al. Aeromedical helicopter use following the 1989 Loma Prieta earthquake. Aviat Space Environ Med 1995:359-63.

39. Matsumoto H, Motomura T, Hara $\mathrm{Y}$, et al. Lessons learned from the aeromedical disaster relief activities following the great east Japan earthquake. Prehosp Disaster Med 2013;28:166-9.
40. Nates JL. Combined external and internal hospital disaster: impact and response in a Houston trauma center intensive care unit. Crit Care Med 2004;32:686-90.

41. Nocera A, Dalton M. Disaster alert! The role of physician-staffed helicopter emergency medical services. Med J Aust 1994;161:689-92.

42. Oestern $\mathrm{HJ}$, Huels $\mathrm{B}$, Quirini $\mathrm{W}$, et al. Facts about the disaster at Eschede. J Orthop Trauma 2000;14:287-90.

43. Pokorny JR. Flood disaster in the Czech Republic in July, 1997operations of the emergency medical service. Prehosp Disaster Med 1999;14:32-4.

44. Romundstad L, Sundnes KO, Pillgram-Larsen J, et al. Challenges of major incident management when excess resources are allocated: experiences from a mass casualty incident after roof collapse of a military command center. Prehosp Disaster Med 2004;19:179-84.

45. Schwartz D, Bar-Dayan Y. Injury patterns in clashes between citizens and security forces during forced evacuation. Emerg Med J 2008;25:695-8.

46. Sollid SJ, Rimstad R, Rehn M, et al. Oslo government district bombing and Utøya island shooting July 22, 2011: the immediate prehospital emergency medical service response. Scand J Trauma Resusc Emerg Med 2012;20:3. http://www.sjtrem.com/content/20/1/3 (accessed 4 Sep 2015).

47. Urquieta E, Varon J. Mexico City's Petroleos Mexicanos explosion: disaster management and air medical transport. Air Med $J$ 2015;33:309-13.

48. Yi-Szu W, Chung-Ping H, Tzu-Chieh L, et al. Chest injuries transferred to trauma centres after the 1999 Taiwan earthquake. Am J Emerg Med 2000;18:825-7.

49. Almersjø O, Ask E, Brandsjo $\mathrm{K}$, et al. Branden på passagerarfärjan Scandinavian Star den 7 april 1990. Socialstyrelsen, 1998:1-51. https://www.socialstyrelsen.se/Lists/Artikelkatalog/Attachments/ 12697/1997-3-15.pdf (accessed 01 Oct 2015)

50. Brandsjø K, Haggmark T, Kulling P, et al. Kamedo- 68. Estoniakatastrofen. Socialstyrelsen. SoS- rapport 1997:15. 2010:1-172.

51. Martin TE. The Ramstein Airshow Disaster. J R Army Med Corps 1990;136:19-26.

52. Nicholas RA, Oberheide JE. EMS response to a ski lift disaster in the Colorado mountains. J Trauma 1988;28:672-5.

53. Nia MS, Nafissi N, Moharamzad Y. Survey of Bam earthquake survivors' opinions on medical and health systems services. Prehosp Disaster Med 2008;23:263-8.

54. Liberati A, Altman DG, Tetzlaff J, et al. The PRISMA statement for reporting systematic reviews and meta-analyses of studies that evaluate health care interventions: explanation and elaboration. PLoS Med 2009;6:1-28.

55. Nocera A. Australian major incident nomenclature: it may be a 'disaster' but in an 'emergency' it is just a mess. ANZ J Surg 2001:71:162-6.

56. Advanced Life Support Group. Major incident medical management and support, the practical approach. Plymouth, UK: BMJ Publishing Group, 2011.

57. Lennquist S. Medical response to major incidents and disasters. Berlin Heidelberg: Springer, 2012.

58. Fattah S, Rehn M, Lockey D, et al. A consensus based template for reporting of pre-hospital major incident medical management. Scand $J$ Trauma Resusc Emerg Med 2014;22:5.

59. Jick TD. Mixing qualitative and quantitative methods: triangulation in action. Adm Sci Q 1979;24:602-11.

60. Merry AF, Davies JM, Maltby JR Qualitative research in health care. Br J Anaesth 2000;84:552-5.

61. Hardy S. Major incidents in England. BMJ 2015;350:1712. 